\title{
HPLC analysis and Bio-kinetics Study of Pyrazinamide in Healthy Volunteers After Oral Administration
}

\author{
Bushra Munir, Bilal Ahmed, Abdul Ghaffar, Tahira Iqbal, Naila Rafiq, Farah Latif \\ Department of Applied chemistry and Biochemistry, Govt. College University Faisalabad, Faisalabad, Pakistan
}

Email address:

bushramunirje@hotmail.com (B. Munir), bilalahmed814@gmail.com (B. Ahmed)

\section{To cite this article:}

Bushra Munir, Bilal Ahmed, Abdul Ghaffar, Tahira Iqbal, Naila Rafiq, Farah Latif. HPLC Analysis and Bio-kinetics Study of Pyrazinamide in Healthy Volunteers After Oral Administration. Science Research. Vol. 3, No. 3, 2015, pp. 89-92. doi: 10.11648/j.sr.20150303.17

\begin{abstract}
Pyrazinamide is use for the treatment of tuberculosis in all over the world. Bio kinetics deals with the mathematical description of drug changes in the body with time function. This study was designed to investigate the bio kinetics of Pyrazinamide after oral administration of Pyrazinamide (25mg) tablet in 10 healthy volunteers. The blood samples of each volunteer were collected from 0.5 to 12 hours at different time intervals after the medication. The concentration of Pyrazinamide in plasma samples were determined by high performance liquid chromatography (HPLC). Quantitative observations were recorded that include the mean $\pm \mathrm{SD}$ value of absorption rate constant $(\mathrm{Ka})$, time to peak $\left(\mathrm{T}_{\max }\right)$ and peak concentration $\left(\mathrm{C}_{\max }\right)$ were $0.38 \pm 0.25 / \mathrm{h}, 2.248 \pm 0.64 \mathrm{~h}$ and $4.165 \pm 2.13 \mu \mathrm{g} / \mathrm{mL}$, respectively. The mean $\pm \mathrm{SD}$ values of absorption half-life $\left(t_{1 / 2} \alpha\right)$ and elimination half-life $\left(t_{1 / 2} \beta\right)$ were $2.078 \pm 1.678 \mathrm{~h}$ and $0.2908 \pm 1.721$ hours. The mean \pm SD values of volume of distribution and total body clearance were $40 \pm 27.4 \mathrm{~L}$ and $3.351 \pm 1.27 \mathrm{~h}$, respectively. Mean residue time (MRT) showed mean $\pm \mathrm{SD}$ and area under curve (AUC) were $17.23 \pm 12.78 \mathrm{~h}$ and $90.4 \pm 76.2 \mathrm{~h} . \mathrm{mg} / \mathrm{L}$, respectively.
\end{abstract}

Keywords: Tuberculosis, HPLC, Bio Kinetics, Pyrazinamide

\section{Introduction}

Pyrazinamide is an important front-line drug for the treatment of tuberculosis (TB). Pyrazinamide, along with isoniazid and rifampicin, forms the cornerstone of modern TB therapy. Pyrazinamide plays a unique role in shortening the therapy from previously 9-12 months to 6 months, because it kills a population of semi-dormant tubercle bacilli in acidic $\mathrm{pH}$ environments that are not killed by other TB drugs. Pyrazinamide is a paradoxical and unconventional drug. Despite its remarkable sterilizing activity in vivo, pyrazinamide is not active against Mycobacterium tuberculosis under 'normal' culture conditions near neutral $\mathrm{pH}$. Pyrazinamide is only active against $\mathrm{M}$. tuberculosis at acid $\mathrm{pH} 10$ and environment that is produced during active inflammation and its activity is closely related to the acidity of the medium. Currently, it is difficult to identify the sterilizing effects of old and new anti-TB drugs in short-term clinical trials because of the difficulty of separating the sterilizing activity of a single drug from that of multiple drugs used for therapy. One solution is a preclinical TB model in which the sterilizing effect can be studied and the results can be translated to the treatment of patients.
Unfortunately, there are several problems in that regard. To begin with, the exact $\mathrm{pH}$ under which $\mathrm{SRB}$ survive in patients with TB is unknown. A pH range of 5.0 to 7.4 either has been measured in cavities containing M. tuberculosis or has been utilized for in vitro studies.

\section{Materials and Methods}

The studies were conducted to analyze the concentration of pyrazinamide in the blood of seven female volunteers after oral administration of pyrazinamide.

\subsection{Pyrazinamide}

Pyrazinamide was obtained in the form of fixed dose combination tablet rim star, Sandoz manufactured by Novartis pharmacy, LTD Jamsharo, Pakistan. The tablet contained isoniazid (75mg), Rifampicin (150mg), Pyrazinamide (400 mg) and Ethambutol hydrochloride $(275 \mathrm{mg})$.

\subsection{Subjects}

The ten female volunteers for this study were the students 
of university of agriculture, Faisalabad. Each volunteer was apprised of the design of the study, dosing and sampling protocol. The volunteers who willingly offered to participate were included in the study. The volunteers were kept fasting for 12 hours and after which the collection of normal or blank samples of blood were taken. The volunteers were allowed to take the Pyrazinamide tablets $3 \times 400 \mathrm{mg}$ each through the oral route.

\subsection{Collection of Blood Samples}

Before drug administration, sterilized plastic branula was inserted intravenously and about $5 \mathrm{ml}$ blood was collected in heparinized plastic centrifuge tube. The blood samples of each volunteer were collected at $0.5,1,1.5,2,2,5,3,4,6,8$, 10 and 24 hours after taken drug. The blood samples were centrifuged at $4000 \mathrm{rmp}$ for 15 minutes. Plasma was carefully by pasture pipette and stored an glass tubes in freezer at $20^{\circ} \mathrm{C}$ until analysis. Pyrazinamide concentration in plasma samples was determined by HPLC method described by Revenger et al, (1994). Chromatography was performed with a high performance liquid chromatography. The HPLC (Waters, $600 \mathrm{E}$ ) was used using an isocratic mode, UV detector $268 \mathrm{~nm}, \mathrm{C}_{18}$ BDS HYPERSIL $(250 \times 4.6)$ column. Flow rate was maintained at $1.0 \mathrm{~mL} / \mathrm{min}$ having run time of $15 \mathrm{~min}$ and retention time $5 \mathrm{~min}$.

\subsection{Statistical Calculations}

The Plasma concentration time data was analyzed by twocompartment model, by using computer program. APO MW/PHARM version 3.02 (Holland, 1987).Graphs and tables have been prepared in Microsoft9 ${ }^{\circledR}$ Excel Version 2002 (10.2614.2625. The mean values and standard deviation (SD) for each pharmacokinetic parameter were calculated in Microsoft Excel.

\section{Results}

These findings of pharm kinetics of pyrazinamide were got after determination of plasma concentration with HPLC. It is total area of plasma concentration verses time curve (from $t_{0}$ -

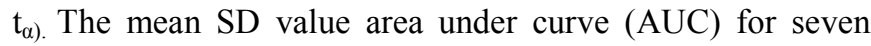
volunteers was $688098 \pm 173074$ h.mg/L and ranged between 413090 and 93610 h.mg/L. The mean \pm SD value of lag time was $0.21 \pm 0.12 \mathrm{~h}$ and it ranged between 0.00 to $0.33 \mathrm{~h}$.

The plasma concentration of pyrazinamide in ten female volunteers was $29.9 \mathrm{mg} / \mathrm{L}$ (Table: 1). A mean representative plot of mean \pm SD cumulative \%age versus time (h0 data is shown in Fig. 2. The bio disposition kinetics was determined after two compartmental model presented. The mean absorption half-life $\left(\mathrm{t}_{1 / 2} \alpha\right)$ of pyrazinamide was $1.81 \pm 2.53$ hand ranged between 0.26 to $7.82 \mathrm{~h}$. The mean $\pm \mathrm{SD}$ value of absorption rate constant of pyrazinamide after oral administration was $1.07 \pm 0.85 \mathrm{~L} / \mathrm{h}$ and ranged between 0.09 to $2.66 \mathrm{~L} / \mathrm{h}$. The mean $\pm \mathrm{SD}$ value for time to peak plasma concentration $(\mathrm{T} / \mathrm{max})$ was $2.85 \pm 1.84 \mathrm{~h}$ and it ranged between 1.04 to $6.99 \mathrm{~h}$. The mean $\pm \mathrm{SD}$ volume of distribution $(\mathrm{V} / \mathrm{d})$ in present study was $28.15 \pm 8.44 \mathrm{~L}$ and ranged between 14.43 to $43.42 \mathrm{~L}$. The mean $\pm \mathrm{SD}$ volume of blood cleared of the drug by various elimination processes (biotransformation and excretion per unit time) was $1.84 \pm$ $0.54 \mathrm{~L} / \mathrm{h}$. The range of total body clearance was found to be between 1.20 to $2.90 \mathrm{~L} / \mathrm{h}$. Its mean $\pm \mathrm{SD}$ value was $1.01 \pm$ $0.79 \mathrm{~L} / \mathrm{h}$. The range of elimination rate constant was between 0.00 to $2.29 \mathrm{~L} / \mathrm{h}$. The biological half-life is the time required for $50 \%$ of the drug to be eliminated from the body after distribution equilibrium has been attained. The mean $\pm \mathrm{SD}$ value and ranged between 2.80 to $15.60 \mathrm{~h}$. It represents the time at which area under curve (AUC) value measured in the plasma is achieved. The MRT was $17.31 \pm 3.04 \mathrm{~h}$. It ranged between 13.84 to $22.89 \mathrm{~h}$.

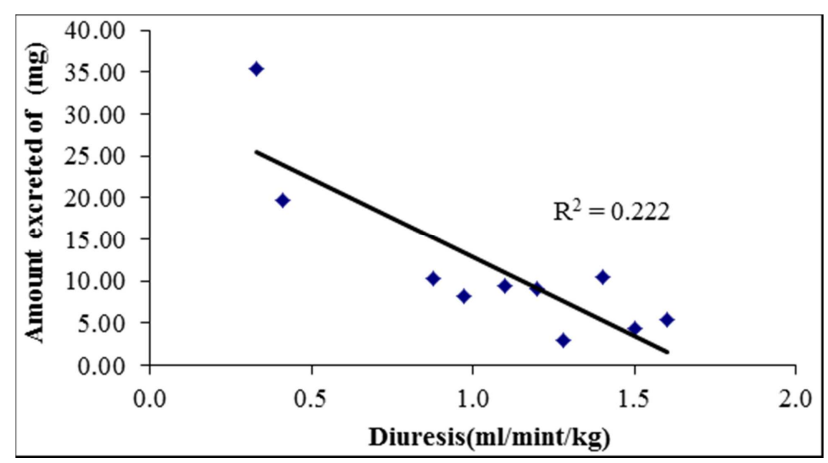

Fig 1. Pyrazinamide amount excreted verses diuresis.

\section{Discussion}

The blood samples collected at different time intervals were analyzed for the drug concentration. The drug concentration versus time data for the determination of bio disposition kinetic parameters are following an oral dose of $1200 \mathrm{mg}$ of pyrazinamide, the mean \pm SD plasma concentration at 30 minutes was $17.1 \pm 7.8 \mu \mathrm{g} / \mathrm{ml}$. The plasma concentration increased with time and showed mean $\pm \mathrm{SD} C$ $\max 23.97$ to $55.70 \mu \mathrm{g} / \mathrm{ml}$ at $\mathrm{T} / \mathrm{max}_{\max }($ mean $\pm \mathrm{SD}) 2.85 \pm 1.84$ hours.

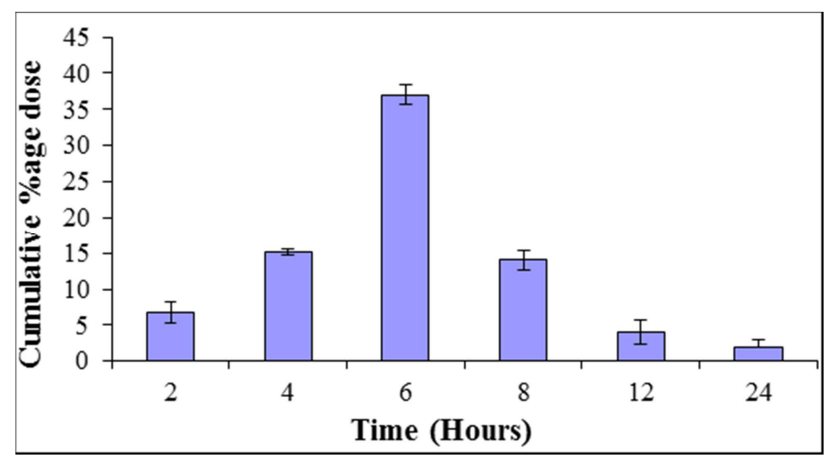

Fig 2. Pyrazinamide cumulative \%age dose verses time.

The first part of the curve shows a gradual increase of the drug concentration and after the maximum peak there was a decline in the concentration $\left(\mathrm{C}_{\max }\right)$ of the drug in plasma. (Peloquin et al., 1997) studied the pharmacokinetics of pyrazinamide (PZA) $1500 \mathrm{mg}$ after oral administration in the 
plasma of healthy males as part of randomized cross-over and found the PZA a median $\mathrm{C}(\max )$ of $2.80 \mathrm{microgram} / \mathrm{ml}$, a $\mathrm{T}(\max )$ of $1.0 \mathrm{~h}$, and $\mathrm{t}_{1 / 2}$ of $10.0 \mathrm{~h}$. Volume of distribution is defined as that volume of fluid required to contain amount of drug in the body, if it was uniformly distributed at a concentration equal to that in plasma. The assumption made shows that body acts as single homogenous compartment with respect to drug. The apparent volume of distribution is not represented as actual volume but serve as proportionality constant relating concentration of drug in plasma at any time after distribution equilibrium has been attained to the amount present in the body (Baggot, 1997). The (mean \pm SD) Volume of distribution following an oral dose of $1200 \mathrm{mg}$ of pyrazinamide was $28.15 \pm 8.44$ liters. (Chan and Wong 1988) studied the volume of distribution in rabbits after an oral and intravenous dose after $\mathrm{i}-\mathrm{v}(3.211+/-0.4121)$ than after oral (5.936 +/-1.6071) administration. The elimination $t 1 / 2$ of PZA in CSF was nearly identical to that in plasma after either i.v. $(1.07+/-0.20 \mathrm{~h})$ or $(1.84+/-0.56 \mathrm{~h})$ administration. The difference of present value of $\mathrm{V}_{\mathrm{d}}$ from other values of $\mathrm{V}_{\mathrm{d}}$ may be due to species difference. After the oral administration of $1200 \mathrm{mg}$ tablets of pyrazinamide the total body clearance was ranged from 1.20 to $2.90 \mathrm{~L} / \mathrm{h}$ and mean $\pm \mathrm{SD}$ is $1.84 \pm$ 0.54. (Ahmadi et al. 2005) reported that total plasma clearance was $(5.39+/-0.43$ and $14.7+/-1.5 \mathrm{ml} / \mathrm{Kg} / \mathrm{min})$. (Roy et al., 1999) studied total body clearance $20.2+/-16.3$ $\mathrm{ml} /$ minute in children (aged 6 to 12 tears) suffering from pulmonary tuberculosis. The differences are shown in value due to age and method. After the oral administration of 1200 $\mathrm{mg}$ of pyrazinamide the mean $\pm \mathrm{SD}$ value of half-life was 2.80 to 15.60 hours. (Zhu, M et al 2002) The studies conducted in tuberculosis patient following oral dose Pharmacokinetic parameters of pyrazinamide were independent of human immunodeficiency virus status and patient demographics, except for body weight. Population elimination half-life values in pediatric and adult patients were 3.5 and 6.0 hours. (Lacroix et al., 1989) determined pharmacokinetics of PZA during hemo-dialysis in 6 patients with chronic renal impairment after a single oral dose of 25.7
(1.9) mg.kg-1. The dialysis clearance of PZA and of its metabolites was: Pyrazinamide $132 \mathrm{ml} . \mathrm{min}-1$; pyrazinoic acid $121 \mathrm{ml} / \mathrm{min}-1$; 5-hydroxy-pyrazinamide 107, l.min-1; 5hydroxy-pyrazinoic acid $118 \mathrm{ml} / \mathrm{min}-1$. The average amount extracted during a dialysis session of $4.1 \mathrm{~h}$ was $926 \mathrm{mg}$ after an oral dose of $1700 \mathrm{mg}$. The high dialyze ability shows that PZA can properly be administrated at the end of each dialysis session in the usual dose of 25 to $30 \mathrm{mg} . \mathrm{kg}-1$.This studies conducted in children (6 to 12 years) suffering from pulmonary tuberculosis after oral administration of pyrazinamide $35 \mathrm{mg} / \mathrm{kg}$ had elimination half-life $10.9+/-4.5$ hours (Roy et al., 1999). This value is lower as compared to present value due to age difference. Area under curve after the oral administration of pyrazinamide was ranged between 413.90 to $936.10 \mathrm{~h}$. $\mathrm{mg} / 1$ and mean $\pm \mathrm{SD}$ value is $688.98 \pm$ 173.74 h.mg/1. (McIlleron el at., 2006) reported of the area under concentration time curve from 0 to $8 \mathrm{~h}$. The absorption rate constant after oral administration of 1200 pyrazinamide (mean $\pm \mathrm{SD}$ ) was ranged between 0.09 to $2.661 / \mathrm{hr}$ and mean $\pm \mathrm{SD}$ value is $1.07 \pm 0.85 \mathrm{l} / \mathrm{hr}$. It represents the time at which area under curve (AUC) value measured is achieved. The MRT ranged between 13.84 to $22.89 \mathrm{hr}$ and mean $\pm \mathrm{SD}$ is $17.31 \pm \mathrm{s} 3.04 \mathrm{hr}$.

\section{Recommendations and Future Scope}

Based on these findings we strongly recommend that dose regimens of imported drugs should be optimized under indigenous conditions. In this work, we used an easy technique and less expensive method for the extraction of drug from plasma samples. Simultaneously this HPLC method for determination of drug is easier, accurate, reproducible, economical and easy to conduct for routine drug analysis as it gives exact concentration of drugs as compared to other routine methods like bioassay, absorptiometry, polarography, TLC and GC with flame ionization detector (FID) and electron capture detector (ECD).

Table 1. Average data of renal clearance

\begin{tabular}{|c|c|c|c|c|c|c|c|c|c|c|}
\hline \multirow[t]{2}{*}{ Volunteers } & \multirow{2}{*}{$\begin{array}{l}\text { Body Wt } \\
\text { Kg } \\
\end{array}$} & \multirow{2}{*}{$\begin{array}{l}\text { Diuresis } \\
\mathrm{ml} / \mathrm{mint} / \mathrm{kg}\end{array}$} & \multicolumn{2}{|l|}{$\mathbf{p H}$} & \multicolumn{2}{|c|}{$\begin{array}{l}\text { Creatinine } \\
\text { concentration }(\mathrm{ug} / \mathrm{ml})\end{array}$} & \multicolumn{2}{|c|}{$\begin{array}{l}\text { Pyrazinamide } \\
\text { concentration }(\mathrm{ug} / \mathrm{ml})\end{array}$} & \multicolumn{2}{|c|}{ Renal clearance $\mathrm{ml} / \mathrm{mint} / \mathrm{kg}$} \\
\hline & & & Urine & Plasma & Urine & Plasma & Urine & Plasma & creatinine & Pyrazinamide \\
\hline 1 & 56.0 & 16.1 & 5.6 & 7.4 & 10.4 & 3.3 & 5.7 & 8.7 & 0.0 & 10.6 \\
\hline 2 & 48.5 & 36.9 & 5.2 & 7.5 & 29.5 & 2.9 & 10.6 & 5.6 & 0.1 & 7.6 \\
\hline 3 & 46.0 & 18.3 & 5.2 & 7.4 & 33.5 & 2.9 & 7.6 & 35.2 & 0.0 & 4.0 \\
\hline 4 & 58.0 & 12.5 & 6.0 & 7.5 & 35.2 & 2.9 & 7.3 & 20.5 & 0.0 & 4.4 \\
\hline 5 & 64.0 & 10.1 & 4.9 & 7.4 & 26.7 & 3.2 & 8.4 & 25.0 & 0.0 & 3.4 \\
\hline 6 & 68.0 & 19.8 & 5.3 & 7.4 & 7.0 & 3.1 & 12.0 & 62.4 & 0.0 & 3.8 \\
\hline 7 & 60.0 & 19.0 & 5.5 & 7.4 & 3.9 & 2.5 & 7.8 & 42.7 & 0.0 & 3.5 \\
\hline 8 & 50.0 & 41.7 & 5.0 & 7.3 & 11.6 & 2.5 & 8.0 & 42.9 & 0.1 & 7.7 \\
\hline 9 & 59.0 & 12.7 & 5.3 & 7.4 & 19.7 & 2.9 & 11.6 & 18.9 & 0.0 & 7.8 \\
\hline 10 & 48.0 & 12.7 & 5.2 & 7.5 & 12.3 & 3.0 & 7.2 & 36.9 & 0.0 & 2.5 \\
\hline SEM & 2.3 & 3.4 & 0.1 & 0.0 & 3.6 & 0.1 & 0.7 & 5.5 & 0.0 & 6.6 \\
\hline
\end{tabular}




\section{References}

[1] Ahmadi, K. R., M. E. Weale, Z. Y. Xue, N. Soranzo, D. P Yarnall, K. Y. Maruyama, M. Kobayashi, N. W. Wood, N. K. Spurr, D. K. Burns, A. D. Roses, A. M. Saunders and D. B. Goldstein. 2005. A single Nucleotide polymorphism tagging set for human drug metabolism and transport. Nat. Genet; 37 : $84-9$.

[2] Barns, P. F., D. L. Lakey and W. J. Burman. 2002. Tuberculosis in patients with HIV infection. Infect. Dis. Clin. N. Am; 16 (1):107-126.

[3] Bhutani, H., S. Singh and K. Chakraborti. 2005. Mechanistic Explanation to the catalysis by pyrazinamide and ethambutol of Reaction between rifampicin and isoniazid in anti-TB FDCs. J. Pharm. Biomed. Anal; 39(5):892-9.

[4] Boshoff, $\mathrm{H}$ and V. Mizarahi. 2000. Expression of Mycobacterium smegmatis Pyrazinamidase in Mycobacterium tuberculosis Confers Hypersensitivity to Pyrazinamide and Related Amides. J. of Bactoriol; 182(19): 5479-85.

[5] Brindle, R., J. Odhiambo and D. Mitchison. 2001. Serial counts of Mycobacterium Tuberculosis in sputum as surrogate markers of the sterilizing activity of rifampicin and pyrazinamide in treating pulmonary tuberculosis. Pulmonary Medicine 1:2: 2466-2.

[6] Davies A. P., O. J Billington, T. D. McHugh, D. A. Murchison and S. H. Gillispie. 2000. Comparison of phenotypic and genotypic methods for Pyrazinamide susceptibility testing with Mycobacterium Tuberculosis. J. Clin. Microbiol; 38:3686-3688.

[7] Gennaro, M. C., R. Calvino and C. Abrigo. 2001. Ion interaction reagent reversed-phase high performance liquid chromatography determine of anti-tuberculosis drugs and metabolites in biological fluids. J.chromatogr. B. Sci. Appl; 754(2):477-86.

[8] Gurumurthy, P., G. Ramchandran, A. K. H. Kumar, S. Rajjasekaran, C. Padmapriyadarsini. S. Swaminathan, S. Bhagavathy P. Venkatesa L. Sekar A. Mahilmaran, N. Rawi chandranand and P. Paramesh. 2004. Decreased bioavailibility of rifapmsin and other antituberculosis. Drugs in patients with advanced human immunodeficiency virus Disease. Antimicrob agents Chemother; 48(11):4473-5.

[9] Hardman, J. D., L.E. Limbrid and A.G. Gillman. 2001. Goodman and Gillman. The Pharmacological basis of Therapeutics, $10^{\text {th }}$ Edition McGraw-Hill companies, Inc., 1274- 1277.

[10] Krishnamurthy, A., D. Almeida, C. Rodrigues and A. Mehta. 2004. Comparison of Pyrazinamide drug susceptibility of M. tuberculosis by radiometria and enzymatic pyrazinamide assay. I ndian J. Med. Microbiol; 22(3): 166-168.

[11] Lemaitre N., I. Callebaaut, F. Frenois, V. Jarlier and W. Sougakoff. 2001. Study of the Structure -activity relations pyrazinamide (PncA) from Mycobacterium tuberculosis. J. Biochem; 353(3):453-8.

[12] McIlleron, H., P. Wash, A. Burger, J. Norman, P.I. Folb and P. Smith. 2006. Determinations of rifampin, isoniazed, pyrazinamide and ethambutol Pharmacikineticsin a cohort of tiberculosis patients. Antimicrob Agents. Chemother; 50(4):1170-7.

[13] Mehmedagic, A., P. Vertic, S. Menager, C. Tharasse, C. Chabenat, D. Andre, O. Lafont. 2002. Investigation of the effects of the concomitant caffeine Administration on the metabolic disposition of pyrazinamide in rats. Biopharm. Drugs Disposition; 23(5):191-5.

[14] Nishizato, Y., I. Ieiri, H. Suzuki, M. Kimura, K. Kawabata, T.Horata, H. Takane S. Irie, H. Kusuhara, Y. Urasaki, A. Urae. S. Higuchi, K.Otsuboo Y. Sugiyama. 2003. Polymorphism of OATP-C (SLC21A6) and AOT3 (SLC22A8) Genes: consequences for pra-wastatin Pharmacokinetics. Clin. Pharmacol. Ther; 73:554-65.

[15] Perlman, D.C., Y. Segal, S. Rozenkranz, P. M. Rainey , C.A. Peloquin, R.P.Remmel, K. Chirgwin, N. Salomon and R. Hafner. 2004. The Clinical Pharmokinetics of Pyrazinamide in HIV- Infected Persons With tuberculosis. Clin. Infect. Dis; 38:556-564.

[16] Saigal, S., S.R. Ararwal, H.P. Nandeesh and S.K. Sarin. 2001. Safety of an Ofloxacin-based antitubercularreimen for the treatment of Tuberculosis in patients with underlying chronic liver disease: a Preliminary report. J. Gastroenterol. Hepatol; 16(9): 1028-32.

[17] Scorpio A., P. Lindholm-Levy, L. Heifets, R. Gilman, S. Siddiqi, M. Cynamon And Y. Zhang. 1997. Characterization of pncA mutations in Pyrazinamide-resistant Mycobacterium tuberculosis.Antimicrob. Agents. Chemother. 41: 540-543

[18] Sreevatsan, S., X. Pan, Y. Zhang, B. N. Kreiswirth and J. M. Musser. 2004. Mutations- associated with pyrazinamide resistance in pncA of Mycobacterium tuberculosis complete organism. Clin. Infect. Dis: 39(4):488-96.

[19] Van Hest, R., H. Baars, S. Kik, P, van Gerven, M.C. Trompenaars, N. Kalisvaart S. Keizer, M. Borgdorff, M. Mensen and F. Cobelens. 2004. Hepatotoxicity of rifampinpyrazinamide and isoniazid preventive Therapy and tuberculosis treatment. Thesis, Department of Tuberculosis Control, Munipal Health Service, Rotterdam.

[20] Wada, M 2001. Effectiveness and problems of PZAcontaining 6-month regimen For the treatment of new pulmonary tuberculosis patients. Kekkak; 76(1):33-43.

[21] Woo, J., C.L Wong, R. Teoh and K. Chan. 1987. Liquid chromatographic assay For the simultaneous determination of pyrazinamide and rifampicin In serum samples from patients with tuberculosis meningitis. J. Chromatogr; 420(1):73-80.

[22] Zitkova, L., J. Stastna, J. Tousek and J. Viklicky. 1983. Toxicity of Morphazinamide compared with pyrazinamide. Czech. Med; 6:140- 151 .

[23] Zhu., M, J. R. Starke, W. J. Burman, P. Steiner, J.J. Stambaugh, D. Ashkin ,A.E. Bulpitt, S. E. Berning and C. A. Peoquin. 2002. Population Pharmacokinetics modeling of pyrazinamide in children and adults With tuberculosis. Pharmacotherapy. 22(6):686-95. 